\title{
Geltape method for measurement of work related surface contamination with cobalt containing dust: correlation between surface contamination and airborne exposure
}

\author{
Otto Melchior Poulsen, Erik Olsen, Jytte Molin Christensen, Peter Vinzent, \\ Ole Holm Petersen
}

\begin{abstract}
Objectives-The geltape method is a new method for optical measurement of total amount of dust on surfaces. The objectives were to study the potential applicability of this method to measurements of work related cobalt exposure during painting of plates with cobalt dye.
\end{abstract}

Methods-Consecutive series of work related geltape prints were taken from surfaces inside and outside the ventilation cabins of two plate painters during two full working days. The amount of dust picked up by the geltapes was measured optically with a field monitor. Also, personal air samples were collected on filters at the different work processes. In the laboratory the contents of cobalt on the geltape prints and the filters were measured with inductive coupled plasma atomic emission spectroscopy.

Results-The key results were: (a) when the geltape prints were taken from surfaces inside the cabins the optically measured area of the geltapes covered with total dust (area (\%)) correlated well with the chemically measured amount of cobalt present on the geltapes. Linear correlation coefficient $\left(R^{2}\right)$ was 0.91 for geltape prints taken on the floor and 0.94 for prints taken on the ceiling; (b) the cumulative airborne cobalt exposure, calculated from data on work related exposure by personal sampling, correlated with the area (\%) of geltape prints taken from the ceiling of the cabin $\left(R^{2}=0.98\right)$; (c) the geltape method could be used to distinguish both between work processes with different levels of cobalt exposure, and between plate painters subjected to significant differences in airborne cobalt exposure.

National Institute of Occupational Health of Denmark, Lersoe Parkallé 105, DK-2100, Copenhagen Ø, Denmark O M Poulsen E Olsen

J M Christensen $P$ Vinzent O H Petersen

Correspondence to: Dr Otto Melchior Poulsen, Department of Toxicology and Biology, National Institute of Occupational Health of Denmark, Lerso Parkallé 105, DK-2100, Copenhagen $\varnothing$, Denmark.

Accepted 7 July 1995
Keywords: geltape assessment; dust exposure, rapid field method

Technically, cobalt is an important metal and cobalt compounds are used in many different ways - for example, as a binding agent in hard metals, as an element in alloys for the production of prostheses and machine parts resistant to high temperatures, as catalysts in chemical processes, in the oil refinery industry, as a blue colour in the porcelain industry, as a dryer in certain paints and varnishes, etc. ${ }^{1-4}$

The National Institute of Occupational Health of Denmark has carried out consecutive studies at Royal Copenhagen for more than 10 years. ${ }^{4}$ The measurements of personal whole day airborne cobalt exposure have been relatively stable at about $24 \mu \mathrm{g} / \mathrm{m}^{3}$ during the past years.

With traditional measurements by collection of air samples through the whole day, the exposure on one day is summed up in one figure and decisions about improvements to be implemented are then based on qualitative estimates of which conditions may have the most important influence on the degree of exposure. ${ }^{5}$ Both collection of air samples and the subsequent chemical analysis of cobalt are time and resource consuming procedures and the traditional method will often limit the number of samples that, in practice, can be collected in connection with a workplace examination thus causing a limited description of the exposure. Controlled studies of employees', employers', and occupational hygienists' abilities to estimate exposure levels based on inspection of work processes and facilities showed that even though the hygienists were doing better than employees and employers, their abilities were not convincing-for example, a clear correlation between estimated and measured exposure was often lacking. ${ }^{6-9}$ A possible explanation when considering dust exposure may be that it is not possible to see inhalable dust with the naked eye. Hence, to obtain a more detailed description of the exposure in the preventive work a simple and cheap method is needed for measurement of dust exposure in work processes of short duration.

The National Institute of Occupational Health of Denmark has recently developed a geltape method for optical measurement of the total amount of dust on surfaces. ${ }^{10}$ Unlike air and biological measurements, the geltape method is very simple and cheap, and thus allows a much more intensive measurement 
programme. If a significant correlation exists between the total amount of dust and the content of cobalt in the dust, the geltape method may be an attractive supplement to air measurements in a routine surveillance of the working environment.

The aim of the present study was to clarify the applicability of the geltape method for measurement of contaminated surfaces, focusing on the correlation between the total amount of surface dust (optical measurement of the relative area of geltape covered with dust) and the content of cobalt in surface dust, and the correlation between the total amount of surface dust and the total exposure to airborne cobalt in different work processes.

\section{Materials and methods \\ SELECTION OF TWO PLATE PAINTERS}

All plate painters perform the same work processes, but previous measurements showed large differences in the cobalt concentration in urine among plate painters. ${ }^{4}$ Two plate painters were selected: painter "low" had a low urine concentration of cobalt in the period 1985-91; painter "high" had a high urine concentration of cobalt in the period 1985-91.

To verify that this difference was still prevalent (and as a part of a study on the urinary excretion of cobalt) all voids of urine from both plate painters were collected separately from Friday morning to the end of the work shift on Thursday. Measurement of creatinine and cobalt concentration in urine with electrothermal atomic absorbtion spectrometry and Zeeman background correction was conducted as described previously. ${ }^{4}$

WORK PROCESSES

Table 1 shows the five principal work processes of one cycle of plate painting. Depending on the motif on the plate, each plate will go through two or more cycles before firing to obtain the final plate. Figure 1 shows schematically the five work processes of plate painting that all plate painters perform in ventilation cabins. The dimensions of each cabin were: width $102 \mathrm{~cm}$, depth $73 \mathrm{~cm}$, height 75 $\mathrm{cm}$. The width of the opening into the cabin during work was $60 \mathrm{~cm}$ and the height was 44 $\mathrm{cm}$. The exhaust outflow in the back of the cabin results in an air velocity in the opening of $0.7-0.8 \mathrm{~m} / \mathrm{s}$.

The two plate painters did not perform the processes in the same way-for example, the

\begin{tabular}{ll} 
Table 1 & Work processes \\
\hline Process & Description \\
\hline Spraying & $\begin{array}{l}\text { Spraying suspended cobalt pigment on plates. The spraygun driven by air } \\
\text { pressure creates a fine aerosol spray of cobalt pigment suspension in water. } \\
\text { After drying of the plates the loose, dry cobalt pigment is swept from the plates } \\
\text { with a large, soft brush. } \\
\text { A small, fine brush is used to brush off paint from the defined parts of the plates } \\
\text { that are going to receive only minute amounts of cobalt pigment (light blue } \\
\text { colour). }\end{array}$ \\
Brushing & $\begin{array}{l}\text { The defined parts of the plates that are going to receive no cobalt (white colour) } \\
\text { is obtained by rubbing off all (dry) cobalt pigment with a small rubber. }\end{array}$ \\
Absorption & $\begin{array}{l}\text { Finally, the white parts are cleaned with a soft cloth. After removal of the plate } \\
\text { the spraygun (without activating the cobalt die outlet) is used to blow the dust } \\
\text { on the cabin floor (excess cobalt pigment and ceramic dust particles) towards } \\
\text { the dust extractor inlets at the rear of the cabin. }\end{array}$ \\
Cleaning &
\end{tabular}

number of plates that were let through each work process before going on with the next process differed between the individual plate painters. This means that the duration of the work processes differed for the different plate painters, and some plate painters postponed a work process until the next day.

\section{GELTAPE METHOD}

\section{Sampling with geltape}

The geltapes are of the type used by the police to obtain finger prints from smooth surfaces (print lifter B-17, Petersen-Bach A/S, DK8850 Bjerringbro, Denmark). Each geltape is composed of a rectangular piece of transparent plastic (length $13 \mathrm{~cm}$; width $18 \mathrm{~cm}$, cut in strips of $3 \mathrm{~cm}$ ) covered with a thin layer of a gelatine based material to obtain a sticky surface. The surface is covered with a removable protective film. The geltape sample is obtained in the following manner. The protective film is removed and the geltape is placed with the sticky surface downwards on the surface to be sampled. The geltape is pressed hard against the surface by rolling a hard rubber roller over the back of the tape.

\section{Optical dust detector}

A technical description of the optical dust detector was previously published. ${ }^{10}$ The portable optical dust detector is designed for field measurements and surveillance. The geltape is placed in a slot in the centre of the apparatus. A parallel light beam from a diode laser $(675 \mathrm{~nm})$ penetrates the geltape perpendicularly. After the geltape the beam is focused and directed through a $1 \mathrm{~mm}$ pinhole to a photodiode for measurement of light intensity. When the parallel light beam hits dust particles on the geltape a fraction of the light will be absorbed by the particles and another fraction will be spread due to diffraction. In this apparatus less than $3 \%$ of the diffracted light will reach the photodiode. Hence, the reduction in intensity of light will reflect the area of dust on the geltape (actually the area of the perpendicular projection of the dust particles).

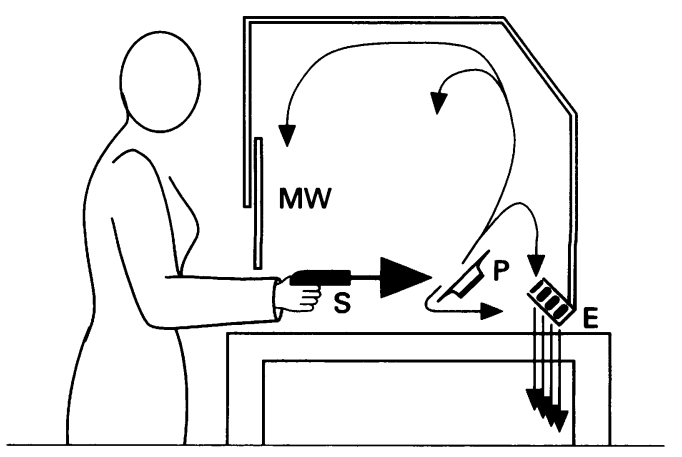

Figure 1 The plate painters' ventilation cabins with air current. Each ventilation cabin is equipped with a movable window (MW) that is closed during spraying and cleaning with air pressure. Also each cabin has a vacuum dust extractor $(E)$ with inlets situated in the cabin floor at the rear of the cabin. The arrows indicate the air current that occur when the plates $(P)$ are sprayed with cobalt dye with the spraygun $(S)$ and when excess dust is removed during cleaning with the spraygun without activating the cobalt dye outlet. Excess cobalt suspension and cobalt containing dust is trapped in the dust extractor and discharged. 
In practice, measurement of dust on the surface of the geltape samples is performed in two steps. The light intensity was measured after penetration through the virgin geltape after the protective film has been removed $\left(I_{0}\right)$. The $I_{o}$ value is stored in the internal memory of the apparatus. After sampling of surface dust the geltape is placed in the slot again (same orientation) and the light intensity after penetration through the geltape with dust is measured $\left(\mathrm{I}_{\text {reduced }}\right)$.

The apparatus is equipped with a calculation unit for automatic transformation of the measured ratio $I_{\text {reduced }} / I_{0}$ into percentage area of the geltape covered with dust (area (\%)). Actually the reduction in light intensity is dependent on the extinction coefficient of the dust particles. As the extinction coefficient is a function of the ratio between the size of the dust particles and the wavelength of the light, the area (\%) is dependent on the size distribution of the particles. For routine surveillance of the relation of surface contamination with the work process this is of limited practical importance unless the size distribution of the dust particles changes profoundly over time. As the field apparatus was used in the present study the data on area (\%) of the geltape covered with dust were recorded.

Proportionality exists between the amount of dust and the measured area (\%) when the area $(\%)$ is less than $25 \%$. When the area (\%) is above $25 \%$ the optical reading no longer gives a valid measure of the dust concentration on the geltapes. Consequently, geltape prints covered with more that $25 \%$ dust were excluded before data analysis of correlation between area covered with dust and cobalt content on the geltape prints.

\section{SAMPLING STRATEGY AND COLLECTION OF SAMPLES}

The sampling strategy had two main aims. Firstly, to obtain data on surface contamination related to work processes with the geltape method, and to elucidate to what extent measurement of surface dust with the geltape method can be used to predict surface cobalt contamination. Secondly, to obtain paired data on airborne exposure and surface contamination in defined work processes, making it possible to elucidate to what extent the surface contamination (measure by geltape prints) correlates with airborne exposure to cobalt containing particles. Included in this strategy was to establish where to take the geltape prints to obtain the best possible correlation with the airborne exposure. Further, the data should make it possible to establish the contribution of the exposure in each work process to the total exposure during the whole working day-that is, the source strength at each work process.

The following samples were collected on two different days.

Day 1

For both painters the airborne cobalt exposure was measured by personal sampling during each work process, and geltape prints were taken inside (ceiling and floor) and outside the cabins to establish where to take the samplesthat is, where there is a good correlation between area (\%) and amount of cobalt on the geltape prints. Also, the airborne cobalt exposure during the whole working day was measured with personal sampling for painter "high", who was anticipated to be subject to the higher exposure. This sample was taken to elucidate to what extent the sum of the measured airborne exposure in the work processes equals the total airborne exposure.

\section{Day 2}

The measurements on day 1 indicated that geltape prints taken from the ceiling inside the cabin reflected the exposure related to work processes better than prints taken from the cabin floor. To obtain more data geltape prints were taken from the ceiling inside the cabins at the end of each work process. In parallel, personal air samples from both plate painters during each work process were taken, and for painter "high" a personal whole day sample was collected.

Personal sampling of airborne particles was performed according to instruction No 2 laid down in 1981 by the Directorate of the Danish Working Environment Service and The National Institute of Occupational Health of Denmark. ${ }^{11}$ Sampling volume was $1.91 / \mathrm{min}$.

\section{CALCULATION OF SIZE DISTRIBUTION OF DUST PARTICLES ON GELTAPE PRINTS}

By microscopy all particles are projected perpendicularly into one plane. In a circular area (diameter $5 \mathrm{~mm}$ ) in the centre of the geltape the size of all projected particles was measured with a video camera coupled to a personal computer with an image processing software CREAM (Kem-En-Tec A/S, Symbion Research Park, Copenhagen). The data were stored in a spreadsheet for later analysis by plots of cumulative size distribution and Kolmogorov-Smirnov two sample test.

\section{CHEMICAL ANALYSIS OF COBALT ON FILTERS AND GELTAPE}

A geltape slice was made from each geltape by fixing the geltape with clamps and cutting a representative rectangular piece $\left(4-5 \mathrm{~cm}^{2}\right)$. Glass knives for microtome cutting of tissue were used to prevent contamination of geltape with cobalt from hard metal knives.

According to the specifications from the supplier the cobalt-aluminate dye, which is insoluble in weak acid, contained $32.5 \%$ cobalt (dry weight). In a preliminary experiment $30 \mathrm{mg}$ dye was added to each of six destruction tubes. The tubes were divided in two groups of three and the following two destruction methods were compared for recovery of cobalt.

\section{NPS acid destruction}

Concentrated $\mathrm{HNO}_{3}(0.4 \mathrm{ml})$, concentrated $\mathrm{H}_{2} \mathrm{SO}_{4}(1.2 \mathrm{ml})$, and concentrated $\mathrm{H}_{3} \mathrm{PO}_{4}$ $(0.8 \mathrm{ml})$ (NPS) were added to the samples. After heating in a sand bath $\left(150^{\circ} \mathrm{C}\right.$ for $60-75$ minutes; $300^{\circ} \mathrm{C}$ for about two hours; then 
Figure 2 Cumulative size distribution of particles on geltape prints taken from the cabin ceilings inside the perpendicular projection of the particles on the geltape prints was measured by microscopy with computerised image processing. cabins. The size of the

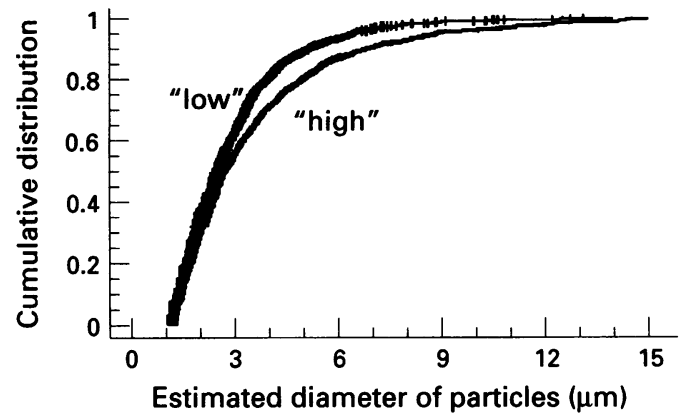

cooling to room temperature) the volume was adjusted to $10 \mathrm{ml}$ with water. The destruction gave a nearly $100 \%$ recovery of spiked cobalt $(92 \cdot 3 \% ; 98 \cdot 1 \% ; 93 \cdot 3 \%)$.

\section{Aqua regia destruction}

Concentrated $\mathrm{HCl}$ and concentrated $\mathrm{HNO}_{3}$ $(4.0 \mathrm{ml}$ of each) (aqua regia) were added to 4 $\mathrm{ml}$ of sample. The same heating procedure in a sand bath was used. After cooling the volume was adjusted to $10 \mathrm{ml}$ with water. The destruction gave only a low recovery $(4 \cdot 8 \%$; $4.5 \%$; sample lost).

Based on the preliminary experiment NPS acid was chosen as the method of destruction of the collected filter and geltape samples. After adjustment of the volume to $10 \mathrm{ml}$ with water each sample was filtered (blue band filters 5893, $90 \mathrm{~mm}$, Schleicher and Shüll), and the cobalt content was measured with inductively coupled plasma atomic emission spectrometry (ICP-AES; Perkin Elmer PII). Cobalt was measured at 238.892 $\mathrm{nm}$ by injection of a sample volume of about $2 \mathrm{ml} .^{12}{ }^{13}$

The cobalt standard solution used $(\mathrm{BDH}$ 14 138) contained $1000 \mu \mathrm{g}$ cobalt per ml. Standard curves (seven standards in the range: $0.05-3.00 \mu \mathrm{g} / \mathrm{ml}$ ) were made by diluting the

Table 2. Geltape prints taken inside the cabin

\begin{tabular}{|c|c|c|c|}
\hline \multicolumn{2}{|c|}{ Plate painter "low" } & \multicolumn{2}{|c|}{ Plate painter "high" } \\
\hline Area (\%) & Cobalt $\left(\mu \mathrm{g} / \mathrm{cm}^{2}\right)$ & Area (\%) & Cobalt $\left(\mu \mathrm{g} / \mathrm{cm}^{2}\right)$ \\
\hline $\begin{array}{l}2 \cdot 6 \\
0 \cdot 7 \\
2 \cdot 5 \\
4 \cdot 1 \\
7 \cdot 1 \\
25\end{array}$ & $\begin{array}{r}1.6 \\
1.1 \\
5.3 \\
13.0 \\
23.2 \\
108.7\end{array}$ & $\begin{array}{r}\text { loor } \\
1 \cdot 0 \\
2 \cdot 2 \\
67 \cdot 3 \\
2 \cdot 4 \\
8 \cdot 7 \\
10 \cdot 2 \\
8 \cdot 9 \\
20 \cdot 8 \\
6 \cdot 6 \\
\end{array}$ & $\begin{array}{c}1 \cdot 4 \\
3 \cdot 3 \\
733 \cdot 3^{\star} \\
13 \cdot 4 \\
1 \cdot 3 \dagger \\
22 \cdot 3 \\
20 \cdot 0 \\
56 \cdot 1 \\
14 \cdot 0 \\
\end{array}$ \\
\hline \multicolumn{2}{|c|}{$\begin{array}{l}\text { Linear regression: } \\
\text { area }(\%) \stackrel{=}{=}[\mathrm{Co}] \times 0.217+1.457 ; R^{2}=0.995\end{array}$} & \multicolumn{2}{|c|}{$\begin{array}{l}\text { Linear regression: } \\
\text { area }(\%)=[\mathrm{Co}] \times 0.367+0.600 ; R^{2}=0.952\end{array}$} \\
\hline \multicolumn{4}{|c|}{$\begin{array}{l}\text { "High" and "low" merged: linear regression: } \\
\text { area }(\%)=[\mathrm{Co}] \times 0.241+1.980 ; R^{2}=0.905\end{array}$} \\
\hline $\begin{array}{l}0 \cdot 7 \\
1 \cdot 4 \\
4 \cdot 2 \\
2 \cdot 6 \\
3 \cdot 7 \\
5 \cdot 2 \\
4 \cdot 5\end{array}$ & $\begin{array}{l}0.4 \\
0.5 \\
3.2 \\
0.7 \\
4.4 \\
3.1 \\
4.3\end{array}$ & $\begin{array}{r}11 \cdot 7 \\
9 \cdot 7 \\
17 \cdot 8 \\
13 \cdot 8 \\
17 \cdot 4 \\
17.9 \\
7.0\end{array}$ & $\begin{array}{r}20 \cdot 3 \\
13 \cdot 1 \\
40 \cdot 3 \\
19 \cdot 0 \\
31 \cdot 6 \\
28 \cdot 8 \\
9.9\end{array}$ \\
\hline \multicolumn{2}{|c|}{$\begin{array}{l}\text { Linear regression: } \\
\text { area }(\%)=[\mathrm{Co}] \times 0.782+1 \cdot 325 ; R^{2}=0.705\end{array}$} & \multicolumn{2}{|c|}{$\begin{array}{l}\text { Linear regression: } \\
\text { area }(\%)=[\mathrm{Co}] \times 0.372+4.956 ; R^{2}=0.854\end{array}$} \\
\hline & \multicolumn{3}{|c|}{$\begin{array}{l}\text { "High" and "low" merged: linear regression: } \\
\text { area }(\%)=[\mathrm{Co}] \times 0.462+2.474 ; R^{2}=0.939\end{array}$} \\
\hline
\end{tabular}

${ }^{\star}$ Excluded as area $(\%)>25 \%$; $\dagger$ : excluded outlier. cobalt standard solution in NPS acid. Samples with a cobalt content exceeding $3.00 \mu \mathrm{g} / \mathrm{ml}$ were diluted in NPS acid (10-fold or more) and analysed again.

\section{Limit of detection-filters}

The mean (SD) of 10 blind filters was $0 \cdot 1096$ $(0.015) \mu \mathrm{g}$. The limit of detection was defined as 3 SDs of measurements of 10 blind filters $(3 \times 0.0150) 0.045 \mu \mathrm{g}$.

\section{Limit of detection - geltape}

As the blind value of cobalt increases with the geltape area, it was considered most correct to express the measured cobalt concentrations in $\mu \mathrm{g}$ cobalt per $\mathrm{cm}^{2}$ geltape. The mean (SD) of 10 virgin geltapes (blind samples) was 0.0620 $(0.0073) \mu \mathrm{g} / \mathrm{cm}^{2}$. The limit of detection was thus $(3 \times 0.0073) 0.0219 \mu \mathrm{g} / \mathrm{cm}^{2}$.

\section{Results}

URINARY COBALT

The measurement of urinary cobalt in samples collected on Friday at the end of the work shift confirmed the anticipated results of the two plate painters. The concentration of cobalt in the urine sample of painter "high" was $5 \mu \mathrm{g} / \mathrm{mmol}$ creatinine $(85 \mathrm{nmol} / \mathrm{mmol}$ creatinine) and the concentration of painter "low" was $0.8 \mu \mathrm{g} / \mathrm{mmol}$ creatinine (14 $\mathrm{nmol} / \mathrm{mmol}$ creatinine). A biomonitoring programme in 1991 on all 107 plate painters showed a mean value of $1.1 \mu \mathrm{g} / \mathrm{mmol}$ creatinine $(18.8 \mathrm{nmol} / \mathrm{mmol}$ creatinine) with the 90th percentile at $2.6 \mu \mathrm{g} / \mathrm{mmol}$ creatinine (43.5 $\mathrm{nmol} / \mathrm{mmol}$ creatinine). ${ }^{4}$ Compared with these values painter "high" was still well above the 90th percentile of cobalt in urine of plate painters, whereas painter "low" was below the mean value of the plate painters.

SIZE DISTRIBUTION OF PARTICLES ON SURFACES A day to day comparison of the size distribution by microscopy of particles on geltape prints from near the front of the ceiling of the cabin showed an unchanged distribution for both painters (Kolmogorov-Smirnov two sample test: painter "high": $P=0.216$; painter "low": $P=0 \cdot 161)$. By mutual comparison the surface contamination in the cabin of painter "low" contained a significantly larger fraction of small particles ( $<5 \mu \mathrm{m}$ diameter of the perpendicular projection of the dust particles) than that of the cabin of painter "high" (Kolmogorov-Smirnov two sample test: $\mathbf{P}=$ 0.00003 , fig 2).

CORRELATION BETWEEN AREA (\%) AND COBALT AMOUNT ON GELTAPE

Table 2 presents the data on area (\%) and amount of cobalt $\left(\mu \mathrm{g} / \mathrm{cm}^{2}\right)$ on geltape prints taken from the floor and the ceiling in the cabins on day 1 and day 2 . The slope of the regression line for the correlation between amount of cobalt and area (\%) was dependent both on where the prints were taken (ceiling $v$ floor of the cabin) and on which plate painter did the work.

Light microscopic examination showed 
Table 3 Airborne exposure and area (\%) on the cabin ceiling in relation to work processes

\begin{tabular}{|c|c|c|c|c|c|c|c|c|c|}
\hline \multicolumn{5}{|l|}{ Painter (day 1) } & \multicolumn{5}{|l|}{ Painter (day 2) } \\
\hline $\begin{array}{l}\text { Time } \\
\text { start-stop }\end{array}$ & Work process & $\begin{array}{l}\text { Exposure } \\
\text { time }\end{array}$ & $\mu g m^{-3}$ & $\begin{array}{l}\text { Area } \\
(\%)\end{array}$ & $\begin{array}{l}\text { Time } \\
\text { start-stop }\end{array}$ & Work process & $\begin{array}{l}\text { Exposure } \\
\text { time }\end{array}$ & $\mu g m^{3}$ & $\begin{array}{l}\text { Area } \\
(\%)\end{array}$ \\
\hline \multicolumn{10}{|l|}{ “Low” } \\
\hline $6.41-14.06$ & Whole day & 445 & 1.60 & - & - & - & - & - & - \\
\hline $6.50-7.23$ & Brushing & 33 & ND & - & $6.40-7.31$ & Brushing & 51 & $1 \cdot 60$ & $2 \cdot 2$ \\
\hline $7.24-10.55$ & Absorption (1st time) & 211 & 0.60 & - & $7.12-12.56$ & Absorption & 248 & 1.60 & $3 \cdot 0$ \\
\hline $10.56-13.50$ & Absorption (3nd time) & 174 & 1.69 & - & $12.14-14.30$ & Sweeping off & 136 & $2 \cdot 10$ & $3 \cdot 6$ \\
\hline \multirow[t]{2}{*}{$13.51-14.06$} & Sweeping & 15 & ND & - & - & & - & - & - \\
\hline & $\begin{array}{l}\text { Accumulated } \\
\text { processes }\end{array}$ & 433 & $1.00(63 \%)$ & $3 \cdot 8$ & & Accumulated & 435 & 1.69 & $3 \cdot 6$ \\
\hline \multicolumn{10}{|l|}{ "High" } \\
\hline $6.32-13.55$ & Whole day-lunch & 401 & $14 \cdot 51$ & - & - & - & - & - & - \\
\hline $6.47-7.02$ & Sweeping & 15 & $3 \cdot 10$ & - & $6.58-7.30$ & Sweeping & 32 & $26 \cdot 11$ & $6 \cdot 3$ \\
\hline $7.03-7.48$ & Spraying & 45 & 1.69 & - & $7.08-8.37$ & Spraying & 89 & $20 \cdot 41$ & - \\
\hline $7.49-7.56$ & Cleaning & 7 & $20 \cdot 60$ & - & $9.09-9.34$ & Brushing & 25 & $2 \cdot 70$ & $8 \cdot 7$ \\
\hline $7.58-8.27$ & Brushing & 29 & $3 \cdot 00$ & - & $9 \cdot 14-14 \cdot 25$ & Absorption & 311 & $25 \cdot 66$ & $23 \cdot 7$ \\
\hline $9.09-13.55$ & Absorption & 286 & $14 \cdot 31$ & - & - & - & - & - & - \\
\hline & $\begin{array}{l}\text { Accumulated } \\
\text { processes }\end{array}$ & 382 & $11 \cdot 61(80 \%)$ & $16 \cdot 5$ & & Accumulated & 457 & $22 \cdot 86$ & $23 \cdot 7$ \\
\hline
\end{tabular}

On both days area (\%) was measured on the ceiling at the end of the working day.

than geltape prints taken outside the cabins had a considerable content of porcelain particles. In general, these geltape prints contained only a low amount of cobalt (generally $<2 \mu \mathrm{g} / \mathrm{cm}^{2}$ ), and the correlation between amount of cobalt and area (\%) was poor (data not shown).

\section{CORRELATION BETWEEN WORK RELATED} AIRBORNE COBALT EXPOSURE AND AREA (\%) ON GELTAPE PRINTS TAKEN ON THE CEILING OF THE CABINS

Table 3 shows the results on personal airborne cobalt exposure at the defined work processes. It was found that painter "high" had the highest airborne cobalt exposure, and that some work processes-for example, absorptioncaused particularly high exposure.

The results of the relation between airborne cobalt exposures and work processes made it possible to calculate the time weighted average exposure for the whole working day. The calculated time weighted average exposure on day 1 turned out to be $63 \%$ for painter "low" and $80 \%$ for painter "high" of the measured whole day personal exposure (table 3).

Table 3 also contains data on the area (\%) of geltape print taken from the cabin's ceiling at the end of each work process on day 2 . Generally a good correlation between area (\%) and airborne exposure related to work processes was found-that is, area (\%) had a tendency to increase profoundly when the

Figure 3 Accumulated airborne cobalt exposure and area (\%) on geltape prints taken from the cabin ceilings. The cobalt exposures at different work processes were measured by personal sampling. At the end of each work process geltape prints were taken from the ceiling of the cabins of both plate painters. plate painters had carried out a work process with high airborne exposure (fig 3 ). When the results of both painter "low" and painter "high" are considered together the overall linear correlation coefficient $\left(R^{2}\right)$ was 0.98 .

\section{Discussion}

In general, personal sampling of airborne compounds (cobalt) and subsequent chemical analysis of the compounds on the filters is too costly to allow a detailed work related exposure description as a part of the routine exposure surveillance. Recently, the National Institute of Occupational Health of Denmark participated in the development of a simple and cheap geltape method for optical determination of surface dust contamination. Airborne particles tend to sediment on and contaminate surfaces, and the aim of the present study was to elucidate the potential applicability of the geltape method for prediction of airborne cobalt exposure at different work processes of plate painting. The main study design was to perform detailed measurements for two plate painters who showed great differences in their working speed (piece rate) and in their personal cobalt exposure as judged from previous biological monitoring results on urinary cobalt. In the present study detailed measurements of cobalt in urine spot samples from Friday morning to Thursday morning confirmed that painter "high" is significantly more exposed to cobalt (sixfold higher peak urinary cobalt on Friday at the end of the work shift) than painter "low".

The plate painters work in ventilation cabins equipped with a vacuum dust extractor with inlets situated in the cabin floor at the rear of the cabin and a movable window which is closed during spraying and cleaning with air pressure (fig 1). As a starting point the working hypothesis was that these two work processes were associated with the highest risk of exposure. We think that if the spraying and cleaning with air pressure is done gently and at a moderate working speed (painter "low") the closed window and the vacuum dust extraction would provide protection, but if the spraygun is used more aggressively and at a 
higher working speed (painter "high") strong turbulence may be created in the cabin and some of the airborne cobalt dye may escape from the cabin at the front. In support of this hypothesis the personal air samples showed that painter "high" was subject to a much higher airborne cobalt exposure than painter "low" (table 3).

Geltape prints taken outside the cabins showed no differences between the two plate painters. In general, these geltape prints had a considerable content of porcelain particles, they contained only low amounts of cobalt, the correlation between the amount of cobalt and area (\%) was poor. Hence, it was concluded that geltape prints taken outside the cabin have little or no predictive value either for surface contamination with cobalt or to airborne cobalt exposure.

For geltape prints taken on the cabin floor a good correlation between amount of cobalt and area (\%) was found for both plate painters. The cabin floor was cleaned during the working day, and the area (\%) showed large variations during the working day. For both plate painters high contamination of the floor with dust and cobalt was occasionally measured (table 2).

Considering the individual plate painters, the correlation between amount of cobalt and area (\%) from the geltape prints taken from the ceiling inside the cabins was not as good as the correlations from the prints taken from the floor. One explanation may be that the size distribution of particles on the cabin floor stays reasonably constant during the sampling period, whereas the size distribution of particles on the ceiling may change during the sampling period perhaps due to changes in work processes. When the data from both painters were merged a good correlation was obtained for the samples taken from the cabin ceiling $\left(R^{2}=0.94\right)$ as well as from the cabin floor $\left(R^{2}=0.91\right)$. In the cabin of painter "high" the measured dust and cobalt contamination of the ceiling was profoundly higher than in the cabin of painter "low" (table 2), perhaps indicating that painter "high" produces a stronger air turbulence. Looking at the slope of the regression line for the correlation between the amount of cobalt on geltape and area (\%) profound differences were found between painter "high" and painter "low" (table 2). These differences probably derived from differences in the size distribution of the dust particles. Larger particles will give a smaller area (\%) per unit of cobalt than smaller particles, and it was anticipated that the particles on the cabin floor are on average larger than on the ceiling. This was confirmed for plate painter "low" (the slope of the regression line for samples taken at the floor was significantly lower than the slope for samples taken at the ceiling). This was not the case for painter "high". Perhaps this painter, who was working at a very high speed, produced a high turbulence in the cabin resulting in more contamination with larger particles on the ceiling. To analyse this in more detail microscopic analyses were conducted on dust particles on geltape prints taken from the cabin ceilings at the end of the working day (fig 2). This analysis showed a significant difference between the two plate painters (the particles on the cabin ceiling of painter "low" were on average smaller than the particles collected at painter "high"). It should be emphasised that the microscopic data on the size distribution of particles on geltapes can not be readily used as an indirect measure of the size distribution of the airborne particles. In the spraying process cobalt pigment suspended in water is sprayed on the plates. Most of the particles of cobalt in water, which may have settled on the ceiling, shrink due to drying during the working day. Furthermore, the aerosol particles that sediment on the ceiling may on average be smaller than the dry cobalt particles produced during the work processes sweeping, brushing, absorption, and cleaning.

In contrast to the cabin floor the ceiling is not cleaned during the working day, and the results obtained on day 1 indicated that dust accumulated on the ceiling during the working day. Consequently, it was decided to focus on geltape prints taken from the ceiling on day 2 as they may better reflect the accumulated surface contamination during work processes and the whole working day. The cabins, including the ceilings, are cleaned daily after working hours. The amount of dust carried over from one day to another is thus limited. Comparison between the data on process related personal exposure to airborne cobalt and area (\%) on geltape prints from the ceiling taken at the end of each process showed a good correlation $\left(R^{2}=0.98\right)$ between area $(\%)$ and accumulated airborne exposure (fig 3 ). The surface dust contamination on the ceiling had a tendency to increase profoundly when the plate painters carried out a work process with high airborne exposure. Consequently, it was shown that measurement of area (\%) on the ceiling was a good predictor of personal exposure to airborne cobalt.

The measurements of the airborne cobalt exposure related to work process showed that the most productive plate painter (painter "high") had a much higher airborne exposure than painter "low" (table 3). On day 1 for painter "high" the work process spraying was divided into spraying and the succeeding process cleaning. On day 2 these two processes were merged. The results from day 1 indicate that even though spraying at first seems to cause a high exposure to aerosols, it is actually the succeeding process cleaning that causes the large exposure. For painter "high" the work process absorption on both days caused a high exposure. As this work process also has the longest duration preventive actions to reduce exposure may with advantage be directed towards this process. The work process sweeping for plate painter "high" was very different on days 1 and 2 . The data are not sufficiently detailed to provide information that can explain this difference.

The present study has indicated that painter "high" performs her work in a manner that creates a strong turbulence inside the cabin 
resulting in high cobalt dust contamination of the ceiling, and, at the same time, a higher personal exposure to airborne cobalt than painter "low". The higher airborne exposure may also be reflected in the higher concentration of cobalt in urine of painter "high". It should be emphasised that other routes of exposure may also be relevant-for example, ingestion or absorption through the skin as recently shown by Scansetti et al..$^{14}$

\section{Conclusions}

In conclusion the present study has shown that: (a) the area on geltape prints covered with total dust taken from surfaces inside the cabins correlates well with the amount of cobalt in the dust trapped on the geltape prints; $(b)$ the area on geltape prints covered with total dust taken from the cabin ceilings correlates with the airborne cobalt exposure; (c) the geltape method can distinguish between work processes with different exposure and between people with (significant) differences in exposure.

All in all the present study indicates that, in this industry, geltape prints from the ceiling of the cabins can be applied in a simple and fast routine surveillance of whole day exposure (end of working day) as well as of exposure related to work processes. In plate painting the aerosols are reasonably well defined with a high content of cobalt dye. Hence, one reason for the successful use of the geltape method in this industry may be that the composition of airborne exposures is preserved over time. In other industries in which the composition of airborne pollutants is more complex, and shows a larger variation over time, the geltape method may not be applied to give an indirect measure of airborne exposure to compounds that are constituents of the airborne dust. For each industry, there should be tests to find out if the geltape method produces results that correlate well with the airborne concentration of the compound of interest. Some basic requirements for a valid application of the geltape method in exposure surveillance are, over time the compound must be a notable fixed fraction of the total dust that is collected on the geltape, geltape prints must be taken from surfaces on which the dust accumulates in proportion to the airborne concentration of dust, and geltape prints must be taken on surfaces that are cleaned at regular intervals so that carry over is limited.

We acknowledge The Danish Work Environment Foundation for supporting the project. We thank laboratory technician Dorrit Meincke for skilful assistance. Chemical engineer Åse Nielsen, Royal Copenhagen, is greatfully acknowledged for help and fruitful discussion in relation to the field measurements.

1 Shirakawa T, Kusaka Y, Fujimura N, Goto S, Kato M, Heki S, Morimoto K. Occupational asthma from cobalt sensitivity in workers exposed to hard metal dust. Chest 1989;95:29-37.

2 International Agency for Research and Cancer (IARC) Chlorinated drinking-water; chlorinated by-products; some other halogenated compounds; cobalt and cobalt compounds. LARC Monogr Eval Carcinog Risk Chem Hum 1991;52:363-450.

3 Michel R, Nolte M, Reich M, Löer F. Systemic effects of implanted prostheses made of cobalt-chromium alloys. Arch Orthop Trauma Surg 1991;110:61-74.

4 Christensen JM, Poulsen OM. A 1982-1992 surveillance programme on Danish pottery painters. Biological levels and health effects following exposure to soluble or insoluble cobalt compounds in cobalt blue dyes. Sci Total Environ 1994;150:94-105.

5 Olsen E. Analysis of exposure using a logbook method. Appl Occup Environ Hyg 1994;9:712-21.

6 Drasche $\mathrm{H}$. Wie genau ist die subjective Schätzung von Staubkonzentrationen? Staub-Reinhalt der Lufi 1971;31: 490-2.

7 Kromhout H, Oostendora Y, Heederik D, Boleij JSM. Agreement between qualitative exposure estimates and quantitative exposure measurements. $A m \mathcal{F}$ Ind $\mathrm{Med}$ 1987;12:551-62.

8 Hawkins NC, Evans JS. Subjective estimation of toluene exposures: a calibration study of industrial hygienists. Appl Ind Hyg 1989;4:61-8.

9 Post W, Kromhout H, Heederik D, Noy D, Duijzent Kunst RS. Semiquantitative estimates of exposure to methylene RS. Semiquantitative estimates of exposure to methylene exposure data. Appl Occup Environ Hyg 1991;6:197-204.

10 Petersen OH, Abildgård A, Kloch NP, Kongsted KS Bunch-Nielsen T. Development of apparatus and method for measurement of dust levels on surfaces. Technical report. Arbejdsmiljøinstituttet og Bygge- og Miljøteknik, Birkerød: Bygge- og Miljøteknik a/s, 1991: 1-50. (In Danish.)

11 The Danish Working Environment Service and The National Institute of Occupational Health, Denmark. Instruction No 2. Sampling of respirable dust and total dust, and volatile compounds of organic solvents. 1981. (In and volatile

12 National Institute of Occupational Health. NIOSH manual of analytical methods, 3rd edition. Methods No 7013 (Al), 7048 (Cd), 7024 (Cr), $7027(\mathrm{Co}), 7029$ (Cu) and 7030 $(Z n)$. Cincinnati: DHHS (Niosh), 1984. (Publ No 84-100.)

13 British Standard Institution. BSD 6691. Fume from welding and allied processes. Part 1. Guide to methods for the sampling and analysis of particulate matter. London: BSI, 1986.

14 Scansetti G, Botta GC, Spinelli P, Reviglione L, Ponzetti C. Absorption and excretion of cobalt in the hard metal industry. Sci Total Environ 1994;150:141-4.

\section{Correspondence and editorials}

Occupational and Environmental Medicine welcomes correspondence relating to any of the material appearing in the journal. Results from preliminary or small scale studies may also be published in the correspondence column if this seems appropriate. Letters should be not more than 500 words in length and contain a minimum of references. Tables and figures should be kept to an absolute minimum. Letters are accepted on the understanding that they may be subject to editorial revision and shortening.

The journal also publishes editorials which are normally specially commissioned. The Editor welcomes suggestions regarding suitable topics; those wishing to submit an editorial, however, should do so only after discussion with the Editor. 